\title{
Correction to: Hospitalization length, surgical duration, and blood lost among the approaches for total hip arthroplasty: a Bayesian network meta-analysis
}

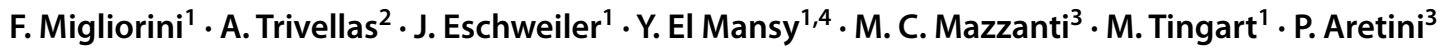

Published online: 4 November 2020

(C) Istituto Ortopedico Rizzoli 2020

\section{Correction to: MUSCULOSKELETAL SURGERY \\ https://doi.org/10.1007/s12306-020-00657-9}

The original version of this article unfortunately contained

a mistake. Typo in author name. Author name should read:

Paolo Aretini and not "Paolo Arentini".

The original article has been corrected.

Publisher's Note Springer Nature remains neutral with regard to jurisdictional claims in published maps and institutional affiliations.

The original article can be found online at https://doi.org/10.1007/ s12306-020-00657-9.

F. Migliorini

migliorini.md@gmail.com

1 Department of Orthopaedics, RWTH Aachen University Clinic, Pauwelsstraße 30, 52074 Aachen, Germany

2 Department of Orthopaedics, David Geffen School of Medicine at UCLA, Suite 755, Los Angeles, CA 90095, USA

3 Fondazione Pisana per la Scienza, Via Ferruccio Giovannini 13, 56017 Pisa, Italy

4 Department of Orthopedics and Traumatology, University of Alexandria, Alexandria, Egypt 